\title{
GAMBARAN PENGETAHUAN IBU HAMIL TENTANG BAYI BERAT LAHIR RENDAH (BBLR) DI PUSKESMAS MASSENGA KECAMATAN POLEWALI KABUPATEN POLEWALI MANDAR
}

\author{
ISTIANA ASRARI BANSU
}

Latar Belakang : Masalah pada neonatus biasanya timbul sebagai akibat yang spesifik terjadi pada masa perinatal. Tidak hanya merupakan penyebab kematian tetapi juga kecacatan Tujuan penelitian : adalah untuk mengetahui gambaran pengetahuan ibu hamil tentang bayi berat lahir rendah (BBLR) di Puskesmas Massenga Kabupaten Polewali Mandar tahun 2015. Metode penelitian : merupakan penelitian yang bersifat deskriptif, subjek penelitiannya yaitu ibu hamil di Puskesmas Massenga. Sedangkan objek penelitiannya adalah gambaran pengetahuan ibu hamil tentang bayi berat lahir rendah (BBLR). Total populasi pada penelitian ini yaitu $85 \mathrm{ibu}$ hamil dengan menggunakan accidental sampling. Alat pengambilan data yang digunakan adalah lembar kuesioner yang terdiri dari 3 sub pertanyaan, yaitu pengertian, tanda-tanda, dan penyebab bayi berat lahir rendah (BBLR).

Simpulan : berdasarkan hasil penelitian didapatkan tingkat pengetahuan ibu hamil tentang bayi berat lahir rendah (BBLR) tingkat berada pada kategori cukup yaitu $47(55,30 \%)$ responden.

Saran : diharapkan kepada petugas kesehatan agar lebih meningkatkan penyuluhan dan ibu hamil dapat lebih menambah informasi dan pengetahuan tentang bayi berat lahir rendah (BBLR)

\section{Kata kunci : pengertian,jenis-jenis dan penyebab bayi berat lahir rendah.}

\section{PENDAHULUAN}

Bayi baru lahir atau neonatus meliputi umur $0-28$ hari. Kehidupan pada masa neonatus ini sangat rawan oleh karena memerlukan penyesuaian fisiologik agar bayi di luar kandungan dapat hidup sebaik-baiknya. Hal ini dapat dilihat dari tingginya angka kesakitan dan angka kematian neonatus. Diperkirakan 2/3 kematian bayi di bawah umur satu tahun terjadi pada masa neonatus. Peralihan dari kehidupan intrauterin ke ekstrauterin memerlukan berbagai perubahan biokimia dan faali. Dengan terpisahnya bayi dari ibu, maka terjadilah awal proses fisiologik (Vivian Nany, 2010).

Banyak masalah pada bayi baru lahir yang berhubungan dengan gangguan atau kegagalan penyesuaian biokimia dan faali yang disebabkan oleh prematuritas, kelainan anatomik, dan lingkungan yang kurang baik dalam kandungan, pada persalinan maupun sesudah lahir (Rukiyah A, 2010).

Masalah pada neonatus biasanya timbul sebagai akibat yang spesifik terjadi pada masa perinatal. Tidak hanya merupakan penyebab kematian tetapi juga kecacatan.Masalah ini timbul sebagai akibat buruknya kesehatan ibu, perawatan kehamilan yang kurang memadai, manajemen persalinan yang tidak tepat dan tidak bersih, kurangnya perawatan bayi baru lahir. Kalau ibu meninggal pada waktu melahirkan, si bayi akan mempunyai kesempatan hidup yang kecil (Rukiyah A, 2010).

Yang termasuk neonatus resiko tinggi yaitu diantaranya sebagai berikut: BBLR, asfiksia neonatorum, sindrom, gangguan pernafasan, ikterus, perdarahan tali pusat, kejang, hypotermi, hypertermi, hypoglikemi dan tetanus neonatorum (Vivian Nany, 2010). 
Dibandingkan dengan bayi dengan berat lahir normal, bayi prematur BBLR lebih banyak mengalami gangguan baik pada masa periode neonatal maupun pada masa perkembangan yang berupa problema wajah neurodevelopmental, problem respiratori, anomali kongenital dan seringnya komplikasi selama perawatan. Hal tersebut dapat berakibat pada kematian bayi dan hambatan perkembangan anak. Sementara itu kelahiran prematur BBLR dapat dipengaruhi oleh kondisi sosial ekonomi, faktor tingkah laku, nutrisi, pemakaian obat-obatan, dan keadaan patologis pada masa kehamilan (Rukiyah A, 2010).

Berat bayi lahir rendah (BBLR) merupakan dampak dari sistem perawatan kesehatan dan pengaruh individu keluarga. Salah satu perawatan kesehatan yang perlu diperhatikan adalah kesehatan rongga mulut selama masa kehamilan. Rongga mulut merupakan tempat yang nyaman bagi perkembangan bakteri. Selama kehamilan, perubahan-perubahan dalam tubuh perempuan hamil akan mempengaruhi kondisi dalam rongga mulut. Perubahan $\mathrm{pH}$ saliva, $\mathrm{pH}$ cairan gingiva dan aktivitas hormon perempuan hamil dalam cairan gingiva akan mempengaruhi perkembangan plak dengan dominasi bakteri anaerob (Herawati, 2009).

Sejak tahun 1961 World Health Organization (WHO) telah mengganti istilah premature baby dengan low birth weight baby (Bayi Dengan Berat Lahir Rendah). Dilakukan karena tidak semua bayi dengan berat kurang dari 2500 gram pada waktu lahir bayi prematur. Menentukan apakah bayi baru lahir itu prematur kita dapat melihat dari Sesuai Masa Kehamilan (SMK), dan (BMK) Besar Masa Kehamilan (Sarwono, 2006).

$$
\text { Prevalensi Bayi Berat Lahir }
$$

Rendah (BBLR) menurut World
Health Organization (WHO) 2010 diperkirakan $15 \%$ dari seluruh kelahiran di dunia dengan batasan 3,3\%-3,8\% dan lebih sering terjadi di negara - negara berkembang atau sosial ekonomi rendah. Secara statistik menunjukkan 90\% kejadian BBLR didapatkan di Negara berkembang dan angka kematiannya 35 kali lebih tinggi dibanding pada bayi dengan berat badan lahir lebih dari 2500 gram. Hal ini dapat terjadi karena dipengaruhi oleh beberapa faktor seperti ibu mempunyai penyakit yang langsung berhubungan dengan kehamilan dan usia ibu (wordpress, 2008).

Secara teori, kesehatan mulut ibu hamil dapat mempengaruhi fetus yang dikandungnya melalui berbagai cara. Kemungkinan mekanisme pertama adalah pada penyakit periodontal infeksi bakteri garam negatif anaerob patogen dari jaringan periodontal dapat mempengaruhi kehamilan dan perkembangan fetus.Mekanisme yang kedua, melalui penurunan pemasukan nutrisi sebagai akibat kesehatan mulut yang buruk. Secara alami mulut yang sakit, akan kurang atau sedikit mengunyah pada waktu makan. Hal ini dapat terjadi karena adanya penyakit periodontal seperti periodontitis, misalnya pregnancy gingivitis (radang gusi) atau sariawan yang sering terjadi pada gusi ibu hamil (Affandi, R, 2006).

Menurut Davenport et al. (1998), pada beberapa penelitian ditemukan bahwa $50 \%$ perempuan hamil mengalami peradangan gingiva serta pembesaran gingiva. Bertambahnya kerentanan terhadap gingivitis selama kehamilan dimulai pada bulan kedua kehamilan, memuncak pada bulan kedelapan dan secara bertahap berkurang pada bulan kesembilan hingga setelah persalinan. Pada tingkat lanjut gingivitis dapat berkembang menjadi periodontitis yang akan mengakibatkan gigi goyang dan 
kemudian lepas dari soketnya (Ali Taqwim, 2009).

Oleh karena itu, kebersihan rongga mulut sebelum dan semasa kehamilan sangat perlu diperhatikan dan dipelihara. Resiko kejadian radang gusi dan penyakit periodontal lainnya dapat diperkecil bila kesehatan dan kebersihan gigi dan mulut pada masa kehamilan selalu terjaga dengan baik (Ali Taqwim, 2009)

BBLR sangat membutuhkan penanganan khusus karena bayi BBLR sangat rentan terjadi infeksi maupun hipotermi. Banyak kasus-kasus yang ada hubungan dengan bayi BBLR ini maupun bayi-bayi bermasalah lainnya dan ini sangat utama sekali karena dapat berakibat pada bayi itu sendiri yaitu akhir dari segalanya adalah kematian. Angka perfalensi BBLR di Indonesia tinggi sekitar 17-25 \% kelahiran hidup $(30-40 \%$ adalah kecil masa kehamilan) (Alimul Hidayat, 2008).

Angka kematian bayi berhasil diturunkan secara tajam dari 68 per 1.000 kelahiran hidup pada 1990 an menjadi 34 per 1.000 kelahiran hidup Survai Demografi dan Kesehatan Indonesia (SDKI 2007). Penurunan kematian neonatal berlangsung lambat yaitu dari 32 per 1.000 kelahiran hidup pada tahun 1990 an menjadi 19 per 1.000 kelahiran hidup (SDKI 2007), dimana $55,8 \%$ dari kematian bayi terjadi pada periode neonatal, sekitar $78,5 \%$ nya terjadi pada umur 0-6 hari (Depkes RI, 2012)

AKB di Provinsi Sulawesi Barat tahun 2013 sebesar 14,5/1000 kelahiran hidup, meningkat bila dibandingkan dengan tahun 2012 sebesar 11,6/1000 kelahiran hidup. Apabila dibandingkan dengan target Nasional 24/1000 kelahiran hidup, maka AKB Provinsi Sulawesi Barat sudah melampaui target Nasional, demikian juga bila dibandingkan dengan target yang diharapkan dalam
MDG (Millennium Development Goals) tahun 2015 yaitu 23/1000 kelahiran hidup (Salehmandar,2013).

Meski Angka Kematian Bayi (AKB) di Kabupaten Polman, Sulawesi Barat (Sulbar), mengalami penurunan.Namun kabupaten ini tetap berada di posisi tertinggi ketimbang kabupaten lainnya di Provinsi Sulbar. Angka kematian bayi (AKB) di Polewali Mandar sebanyak 120 bayi. Sedangkan angka kejadian BBLR di Polewali Mandar total 8355 bayi yang mengalami BBLR sebanyak 352 bayi dan yang lahir normal sebanyak 8003 bayi. Kasus BBLR mengalami peningkatan jika dibandingkan dengan tahun 2013, dimana dari total 8739 bayi yang mengalami BBLR sebanyak 345 bayi dan yang lahir berat normal sebanyak 8394 bayi. (Dinas Kesehatan Polewali Mandar, 2016). Sedangkan angka tertinggi kejadian BBLR yaitu di Puskesmas Massenga dimana didapatkan total431 bayi yang mengalami BBLR sebanyak 48 bayi dan yang lahir dengan berat badan normal sebanyak 383 bayi. Selain itu didapatkan data kematian akibat BBLR di Puskesmas Massenga sebanyak 5 bayi. Sedangkan data yang diperoleh untuk total ibu hamil pada bulan januari sampai desember sebanyak 581 orang (Puskesmas Massenga, 2017).

Pengetahuan ibu hamil tentang bayi berat lahir rendah (BBLR) sangatlah penting untuk diketahui agar bayi terhindar dari resiko kejadian berat bayi lahir rendah (BBLR) sehingga selama hamil ibu diharapkan mampu menjaga pola makan dengan gizi cukup dan seimbang. Selain itu, dengan mengetahui nilai normal dari berat badan bayi yang baru lahir maka ibu akan mampu menilai apakah berat badan bayi dalam kondisi normal atau tidak. 
Berdasarkan studi pendahuluan dilakukan wawancara dengan ibu hamil yang ada di wilayah kerja puskesmas Massenga Kecamatan Polewali Kabupaten Polewali mandar pada bulan februari 2015, dengan melakukan wawancara pada 10 orang ibu hamil tentang bayi berat lahir rendah (BBLR)didapatkan data sebanyak 6 orang ibu hamil $(60 \%)$ mengatakan tidak tahu tentang bayi berat lahir rendah (BBLR), dan 3 orang ibu hamil (30\%) mengatakan cukup tahu tentang bayi berat lahir rendah (BBLR) dan 1 orang ibu hamil (10\%) mengatakan tahu tentang bayi berat lahir rendah (BBLR).

Berdasarkan latar belakang diatas maka penulis tertarik untuk melakukan penelitian mengenai "Gambaran pengetahuan ibu hamil tentang bayi berat lahir rendah (BBLR) di Puskesmas Massenga

\section{HASIL DAN PEMBAHASAN}

Hasil Penelitian
Kecamatan Polewali Kabupaten

Polewali Mandar". METODE PENELITIAN

Jenis dan Metode Penelitian

Penelitian ini menggunakan metode penelitian deskriptif. Penelitian ini dilakukan untuk mendapatkan gambaran pengetahuan ibu hamil tentang bayi berat lahir rendah (BBLR) di Puskesmas Massenga Kecamatan Polewali Kabupaten Polewali Mandar Pada Tahun 2017.

\section{Lokasi dan Waktu Penelitian}

Penelitian ini dilakukan di wilayah kerja puskesmas massenga Polewali Mandar pada bulan Agustus Tahun 2017

Populasi dan Sampel

Populasi dalam penelitian ini adalah ibu hamil yang ada di wilayah kerja Puskesmas Massenga Kecamatan Polewali pada periode Januari sampai dengan Juli 2017 populasi dalam penelitian ini adalah $581 \mathrm{ibu}$ hamil. Serta sampel sebanyak 85 ibu hamil.

Tabel 4.1

Distribusi Frekuensi Responden Menurut Kelompok Umur di Puskesmas Massenga Kecamatan Polewali

\begin{tabular}{|r|r|l|l|}
\hline No & \multicolumn{1}{|c|}{ Umur Responden } & Frekuensi & Persentase $(\boldsymbol{\%})$ \\
\hline 1 & $<20$ & 11 & 12,94 \\
2 & $20-35$ & 68 & 80 \\
3 & $>35$ & 6 & 7,06 \\
\hline \multicolumn{2}{|l|}{ Total } & $\mathbf{8 5}$ & $\mathbf{1 0 0}$ \\
\hline
\end{tabular}

Sumber : Data Primer

Berdasarkan tabel 4.1 tentang umur responden, dimana hasil penelitian menunjukkan bahwa dari 85 responden yang berusia $<20$ tahun sebanyak 11 responden atau $(12,94 \%)$,

yang berusia 20-35 tahun sebanyak 68 responden atau $(80 \%)$, dan yang berusia > 35 tahun sebanyak 6 responden atau $(7,06 \%)$.

Tabel 4.2

Distribusi Responden Berdasarkan Pendidikan

Di Puskesmas Massenga Kecamatan Polewali

\begin{tabular}{|l|l|l|l|}
\hline No & Pendidikan & Frekuensi & Persentase (\%) \\
\hline
\end{tabular}




\begin{tabular}{|l|l|l|l|}
\hline 1 & SD & 0 & 0 \\
2 & SMP & 6 & 7,06 \\
3 & SMA & 61 & 71,76 \\
4 & PT & 18 & 21,18 \\
\hline \multicolumn{2}{|l|}{ Total } & $\mathbf{8 5}$ & $\mathbf{1 0 0}$ \\
\hline
\end{tabular}

Sumber : Data Primer

Berdasarkan tabel 4.2 tentang pendidikan responden, dimana hasil penelitian menunjukkan bahwa dari 85 responden yang berpendidikan SD sebanyak 0 responden atau $(0 \%)$, yang berpendidikan SMP sebanyak 6

responden atau (7,06\%), yang berpendidikan SMA sebanyak 61 responden atau $(71,76 \%)$, dan yang berpendidikan PT ( Perguruan Tinggi) sebanyak 18 responden atau $(21,18 \%)$.

Tabel 4.3

Distribusi Responden Berdasarkan Pekerjaan

Di Puskesmas Massenga Kecamatan Polewali

\begin{tabular}{|l|l|l|l|}
\hline No & Pekerjaan & Frekuensi & Persentase (\%) \\
\hline 1 & PNS & 12 & 14,12 \\
2 & Wiraswasta & 15 & 17,65 \\
3 & IRT & 58 & 68,23 \\
\hline Jumlah & $\mathbf{8 5}$ & $\mathbf{1 0 0}$ \\
\hline
\end{tabular}

Sumber : Data Primer

Berdasarkan tabel 4.3 tentang pekerjaan responden, dimana hasil penelitian menunjukkan bahwa dari 85 responden yang bekerja sebagai IRT sebanyak 58 responden atau
$(68,23 \%)$, yang bekerja sebagai wiraswasta sebanyak 15 responden atau $(17,65 \%)$ yang bekerja sebagai PNS sebanyak 12 responden atau $(14,12 \%)$.

\section{Variabel Yang Diteliti}

\section{Tabel 4.4}

Distribusi Frekuensi Tingkat Pengetahuan Responden

Tentang Pengertian Bayi Berat Lahir Rendah (BBLR)

di Puskesmas Massenga Kecamatan Polewali

\begin{tabular}{|l|l|l|l|}
\hline No & Kategori & Frekuensi & Persentase (\%) \\
\hline 1 & Baik & 30 & 35,29 \\
2 & Cukup & 43 & 50,59 \\
3 & Kurang & 12 & 14,12 \\
\hline \multicolumn{2}{|c|}{ Jumlah } & $\mathbf{8 5}$ & $\mathbf{1 0 0}$ \\
\hline
\end{tabular}

Sumber : Data Primer 
Berdasarkan Tabel 4.4 menunjukkan bahwa pengetahuan responden tentang pengertian bayi berat lahir rendah (BBLR), dimana hasil penelitian menunjukkan bahwa dari 85 responden yang memperoleh kriteria baik sebanyak 30 responden atau $(35,29 \%)$, yang memperoleh kriteria cukup sebanyak 43 responden atau $(50,59 \%)$, dan yang mempunyai kriteria kurang sebanyak 12 responden atau $(14,12 \%)$.

Tabel 4.5

\section{Distribusi Frekuensi Tingkat Pengetahuan Responden Tentang Tanda-Tanda Bayi Berat Lahir Rendah (BBLR) di Puskesmas Massenga Kecamatan Polewali}

\begin{tabular}{|l|l|l|l|}
\hline No & Kategori & Frekuensi & Persentase (\%) \\
\hline 1 & Baik & 20 & 23,53 \\
2 & Cukup & 30 & 35,29 \\
3 & Kurang & 35 & 41,18 \\
\hline \multicolumn{2}{|l|}{ Jumlah } & $\mathbf{8 5}$ & $\mathbf{1 0 0}$ \\
\hline
\end{tabular}

Sumber : Data Primer

Berdasarkan Tabel 4.5 menunjukkan bahwa pengetahuan responden tentang tanda-tanda bayi berat lahir rendah (BBLR), dimana hasil penelitian menunjukkan bahwa dari 85 responden yang memperoleh kriteria baik sebanyak
20 responden atau $(23,53 \%)$, yang memperoleh kriteria cukup sebanyak 30 responden atau $(35,29 \%)$, dan yang mempunyai kriteria kurang sebanyak 35 responden atau $(41,18 \%)$.

Tabel 4.6

Distribusi Frekuensi Tingkat Pengetahuan Responden Tentang Penyebab Bayi Berat Lahir Rendah (BBLR) di Puskesmas Massenga

\begin{tabular}{|l|l|l|l|}
\hline No & Kategori & Frekuensi & Persentase (\%) \\
\hline 1 & Baik & 28 & 32,94 \\
2 & Cukup & 49 & 57,65 \\
3 & Kurang & 8 & 9,41 \\
\hline \multicolumn{2}{|c|}{ Jumlah } & $\mathbf{8 5}$ & $\mathbf{1 0 0}$ \\
\hline
\end{tabular}

Sumber : Data Primer

Berdasarkan Tabel $\quad 4.6$ menunjukkan bahwa pengetahuan responden tentang penyebab bayi berat lahir rendah (BBLR), dimana hasil penelitian menunjukkan bahwa dari 85 responden yang 
memperoleh kriteria baik sebanyak 28 responden atau $(32,94 \%)$, yang memperoleh kriteria cukup sebanyak 49 responden atau
$(57,65 \%)$, dan yang mempunyai

kriteria kurang sebanyak 8

responden atau $(9,41 \%)$.

\section{Tabel 4.7}

Distribusi Frekuensi Tingkat Pengetahuan Responden Tentang Bayi Berat Lahir Rendah (BBLR) di Puskesmas Massenga

\begin{tabular}{|l|l|l|l|}
\hline No & Kategori & Frekuensi & Persentase (\%) \\
\hline 1 & Baik & 22 & 25,88 \\
2 & Cukup & 47 & 55,30 \\
3 & Kurang & 16 & 18,82 \\
\hline \multicolumn{2}{|c|}{ Jumlah } & $\mathbf{8 5}$ & $\mathbf{1 0 0}$ \\
\hline
\end{tabular}

Sumber : Data Primer

Berdasarkan Tabel 4.7

menunjukkan bahwa pengetahuan responden tentang bayi berat lahir rendah (BBLR), dimana hasil penelitian menunjukkan bahwa dari 85 responden yang memperoleh

\subsection{Pembahasan}

\subsubsection{Karakteristik Responden}

Hasil penelitian yang dilakukan terhadap 85 responden, memperlihatkan bahwa responden memiliki latar belakang yang sangat bervariasi dari segi umur, pendidikan dan pekerjaan.

\subsubsection{Umur}

Berdasarkan tabel 4.1 tentang umur responden, ternyata dari 85 responden 11 responden atau $(12,94 \%)$ yang berusia $<20$ tahun, sebanyak 68 responden atau (80\%) yang berusia 20-35 tahun, dan sebanyak 6 responden atau $(7,06 \%)$ yang berusia >35 tahun. Hal ini menujukkan bahwa pengetahuan seseorang terhadap objek ditentukan oleh kecenderungan untuk memberikan nilai tertentu atau sejauh mana objek tersebut bernilai bagi dirinya (Notoadmojo, 2003). Berdasarkan karakteristik umur menunjukkan bahwa pada kelompok umur tersebut responden kriteria baik sebanyak 22 responden atau $(25,88 \%)$, yang memperoleh kriteria cukup sebanyak 47 responden atau $(55,30 \%)$, dan yang mempunyai kriteria kurang sebanyak 16 responden atau $(18,82 \%)$.

terbanyak berada pada usia subur adapun perbedaan tentang pemilikan pengetahuan lebih disebabkan oleh adanya perbedaan tingkat motivasi dari kader itu sendiri.

Umur adalah usia individu yang terhitung mulai saat dilahirkan sampai saat beberapa tahun. Semakin cukup umur tingkat kematangan dan kekuatan seseorang akan lebih matang dalam berpikir dan bekerja dari segi kepercayaan masyarakat yang lebih dewasa akan lebih percaya diri pada orang belum cukup tinggi tingkat kedewasaanya.

\subsubsection{Pendidikan}

Berdasarkan tabel 4.2 tentang pendidikan responden, ternyata dari 85 responden 0 responden atau $(0 \%)$ yang berpendidikan SD,sebanyak 6 responden atau $(7,06 \%)$ yang berpendidikan SMP, sebanyak 61 responden atau $(71,76 \%)$ yang berpendidikan SMA, sebanyak 18 responden atau $(21,18 \%)$ yang perpendidikan PT (Perguruan Tinggi). 
Hal tersebut di atas menandakan bahwa proses kognitif yang mengawali terjadinya proses tahu atau pengetahuan seseorang dipengaruhi oleh faktor internal (pribadi) dan faktor eksternal (lingkungan) faktor internal seseorang meliputi pengalaman, pengetahuan, proses belajar, wawasan, pemikiran, keinginan, motivasi dan tujuan. Sedangkan faktor eksternal meliputi lingkungan keluarga, fisik, dan sosial budaya (Notoadmojo, 2006).

Jika dikaitkan dari segi karakteristik pendidikan responden, dimana dari hasil penelitian diperoleh presentase pendidikan tertinggi yaitu SMA sebanyak 61 responden atau $(71,76 \%)$, namun pengetahuan ibu hamil tentang bayi berat lahir rendah (BBLR) masuk dalam kategori cukup, hal ini bertolak belakang dengan pendidikan responden, sehingga dapat peneliti menyimpulkan pendidikan yang tinggi tidak dapat menjadi patokan responden tersebut mempunyai pengetahuan yang cukup tentang bayi berat lahir rendah (BBLR). Pengetahuan cukup dapat dipengaruhi oleh pengalaman dan kamauan responden untuk mencari informasi, dimana responden masih membutuhkan pengetahuan sehingga diharapkan ibu hamil mampu melakukan deteksi dini dengan cara melakukan pemeriksaan kehamilan secara rutin sehingga kejadian bayi berat lahir rendah (BBLR) dapat dicegah.

Pendidikan adalah usaha yang sadar untuk mengembangkan kepribadian dan kemampuan didalam dan diluar sekolah dan berlangsung seumur hidup. Pendidikan pada dasarnya memiliki pusat-pusat pendidikan yang disebut Tripusat seperti yang dikemukakan oleh $\mathrm{Ki}$ Hajar Dewantoro. Tripusat ini meliputi :

$$
\text { a. Lingkungan kerja }
$$

Pendidikan keluarga merupakan jalur pendidikan di luar sekolah yang diselenggarakan dalam keluarga dan yang memberikan keyakinan agama, nilai budaya, nilai social, dan keterampilan. b. Perguruan dan Lembaga Pendidikan

Lingkungan sekolah dengan struktur dan system pendidikan yang khas. Pendidikan dalam sekolah ini meliputi :

1) Pendidikan Rendah (Sekolah Dasar 6 Tahun)

2) Pendidikan Menengah (SMP, SMA, dan SMK)

3) Perguruan Tinggi (Akademi/Sarjana)

c. Lingkungan Masyarakat

Yaitu lingkungan masyarakat sekitar dengan segala dinamika dan karakteristik yang secara langsung ataupun tidak langsung mempengaruhi perkembangan anak didik sebagai anggota masyarakat.

Pendidikan mempengaruhi proses belajar, makin tinggi pendidikan sesorang makin mudah orang tersebut untuk menerima informasi. Dengan pendidikan tinggi maka seseorang akan cenderung untuk mendapatkan informasi baik dari orang lain maupun dari media massa, sebaliknya tingkat pendidikan yang kurang akan menghambat perkembangan dan sikap seseorang terhadap nilai-nilai yang baru diperkenalkan, ketidaktahuan dapat disebabkan karena pendidikan rendah, seseorang dengan tingkat pendidikan yang terlalu rendah akan sulit menerima pesan, pencerna pesan informasi yang disampaikan (InfoKes, 2009).

Tingkat pendidikan ibu hamil yang rendah mengakibatkan kurangnya pengetahuan ibu hamil dalam menghadapi masalah, pengetahuan diperoleh baik secara formal maupu informal, sedangkan responden yang mempunyai tingkat pendidikan yang tinggi umumnya terbuka menerima perubahan atau hal-hal yang baru guna pemeliharaan kesehatannya. Pendidikan merupakan upaya persuasi atau pembelajaran kepada masyarakat agar masyarakat mau melakukan tindakantindakan atau praktek untuk memlihara (mengatasi masalah) dan meningkatkan kesehatannya. Perubahan atau tindakan pemeliharaan dan peningkatan kesehatan yang dihasilkan oleh pendidikan kesehatan ini didasarkan oleh pengetahuan dan 
kesadarannya melalui proses pembelajaran, sehingga perilaku tersebut diharapkan akan berlangsung lama dan menetap karena didasari oleh kesadaran (InfoKes, 2009).

\subsubsection{Pekerjaan}

Berdasarkan tabel 4.3 di atas tentang pekerjaan responden, dimana hasil penelitian menunjukkan bahwa dari 85 responden 58 responden atau $(68,23 \%)$ yang bekerja sebagai IRT, sebanyak 15 responden atau $(17,65 \%)$ yang bekerja sebagai wiraswasta dan yang bekerja sebagai PNS sebanyak 12 responden atau $(14,12 \%)$. Hal ini menunjukkan bahwa pengetahuan seseorang terhadap objek ditentukan oleh kecenderungan untuk memberikan nilai tertentu atau sejauh mana objek tersebut bernilai bagi dirinya (Notoadmojo, 2003).

Pekerjaan ibu hamil sebagai IRT diperkirakan dapat mempengaruhi pengetahuannya tentang bayi berat lahir rendah (BBLR) karena kesibukan mengurusi pekerjaan rumah sehingga kurang mendapatkan informasi, kurangnya sosialisasi dan biasanya ibu hamil tidak memiliki waktu yang luang untuk mengukitu penyuluhan termasuk yang berkaitan dengan kesehatan ibu dan bayi selama hamil dan untuk mencari pengetahuan dan pengalaman tentang halhal yang berhubungan dengan bayi berat lahir rendah (BBLR) setelah mengurusi pekerjaan rumah.

\subsubsection{Tingkat Pengetahuan Ibu Hamil Tentang Pengertian Bayi Berat Lahir Rendah (BBLR)}

Bayi berat lahir rendah (BBLR) adalah bayi baru lahir yang berat badanya saat lahir kurang dari 2500 gram (sampai dengan 2499 gram) tanpa memandang masa kehamilan (Ambarwati, 2011).

Hasil penelitian tingkat pengetahuan tentang pengertian bayi berat lahir rendah berdasarkan tabel 4.6 menunjukkan bahwa dari 85 responden yang memperoleh kriteria baik sebanyak 30 responden atau $(35,29 \%)$, yang memperoleh kriteria cukup sebanyak 43 responden atau $(50,59 \%)$, dan yang mempunyai kriteria kurang sebanyak 12 responden atau $(14,12 \%)$. Pada penelitian, peneliti menggunakan 9 pertanyaan tentang pengertian bayi berat lahir rendah (BBLR), dan sebagian besar responden menjawab cukup yaitu sebanyak $43(50,59 \%)$ responden.

Berdasarkan penelitian yang telah dilakukan dapat ditarik simpulan bahwa pengetahuan ibu hamil tentang pengertian bayi berat lahir rendah (BBLR) di Puskesmas Massenga Kecamatan Polewali Kabupaten Polewali Mandar Tahun 2015 berada pada kategori cukup.

\subsubsection{Tingkat Pengetahuan Ibu Hamil Tentang Tanda-Tanda Bayi Berat Lahir Rendah (BBLR)}

Gambaran berat badan lahir rendah tergantung dari umur kehamilan,sehingga makin mudah umur kehamilan makin jelas tanda-tanda prematuritas dengan karakteristik sebagai berikut :

a. Berat badan kurang 2500 gram, panjang badan kurang dari $45 \mathrm{~cm}$, lingkar kepala kurang dari $33 \mathrm{~cm}$, lingkar dada kurang dari $30 \mathrm{~cm}$.

b. Masa gestasi kurang dari 37 minggu.

c. Kepala lebih besar dari badan.

d. Kulit tipis dan transparan, nampak mengkilap dan licin, lemak subkutan kurang.

e. Lanugo banyak terutama pada dahi, pelipis, telinga, dan lengan.

f. Ubun-ubun dan sutura lebar.

g. Genitalia belum sempurna, labia minora belum tertutup oleh labia mayora (pada wanita).pada laki-laki testis belum turun.

h. Pembuluh darah kulit banyak terlihat, pristaltic usus dapat terlihat.

i. Rambut tipis, halus dan teranyam.

j. Tulang rawan dan daun telinga immature (elastis daun telinga masih kurang sempurna).

k. Putting susu belum terbentuk dengan baik.

1. Bayi kecil, posisi masih fetal.

m.Pergerakan kurang dan lemah,otot masih hipotonik. 
n. Banyak tidur, tangis lemah pernapasan belum teratur dan sering terjadi арпи.

o. Refleks tonus leher lemah, refleks menghisap dan menelan serta refleks batuk belum sempurna (Wiknjosastro, 2005).

Hasil penelitian tingkat pengetahuan tentang tanda-tanda bayi berat lahir rendah (BBLR) berdasarkan tabel 4.5 menunjukkan bahwa dari 85 responden yang memperoleh kriteria baik sebanyak 20 responden atau $(23,53 \%)$, yang memperoleh kriteria cukup sebanyak 30 responden atau $(35,29 \%)$, dan yang mempunyai kriteria kurang sebanyak 35 responden atau $(41,18 \%)$.

Pencapaian pengetahuan cukup hal ini disebabkan pendidikan yang rendah dan dilihat dari pekerjaan ibu hamil sebagian besar sebagai ibu rumah tangga dimana mereka masih membutuhkan pengetahuan dan pemahaman tentang kegiatan pelayanan kebidanan khususnya selama kehamilan terutama pengetahuan yang berkaitan dengan kategori bayi berat lahir rendah (BBLR), termasuk pengalaman ibu hamil dalam pengenalanan tanda-tanda bayi berar lahir rendah masih kurang. Hal ini diperkuat oleh Notoatmodjo (2006) bahwa pengalaman merupakan guru yang baik untuk memperoleh pengetahuan.

Berdasarkan penelitian yang telah dilakukan dapat ditarik simpulan bahwa pengetahuan ibu hamil tentang tanda-tanda bayi berat lahir rendah (BBLR) di Puskesmas Massenga Kecamatan Polewali Kabupaten Polewali Mandar Tahun 2015 berada pada kategori kurang.

\subsubsection{Tingkat Pengetahuan Ibu Hamil Tentang Penyebab Bayi Berat Lahir Rendah (BBLR)}

Penyebab terbanyak terjadinya BBLR adalah kelahiran prematur dan disebabkan oleh beberapa faktor yaitu : faktor ibu diantaranya usia ibu dibawa 16 tahun atau lebih dari 35 tahun, paritas, ras, riwayat kehamilan tidak baik, ibu menderita penyakit akut/kronis (DM, tiroid, ginjal, jantung, paru, preeklampsia berat/eklampsia), kebiasaan tidak baik seperti merokok dan minum alcohol, faktor plasenta tumor, kehamilan ganda, serta faktor janin infeksi bawaan, kelainan kromosom (Prawirohardjo, 2007).

Hasil penelitian tingkat pengetahuan tentang penyebab bayi berat lahir rendah (BBLR) berdasarkan tabel 4.6 menunjukkan bahwa dari 85 responden yang memperoleh kriteria baik sebanyak 28 responden atau (32,94\%), yang memperoleh kriteria cukup sebanyak 49 responden atau $(57,65 \%)$, dan yang mempunyai kriteria kurang sebanyak 8 responden atau $(9,41 \%)$.

Berdasarkan penelitian yang telah dilakukan dapat ditarik kesimpulan bahwa pengetahuan ibu hamil tentang penyebab bayi berat lahir rendah (BBLR) di Puskesmas Massenga Kecamatan Polewali Kabupaten Polewali Mandar Tahun 2015 berada pada kategori cukup.

\subsubsection{Tingkat Pengetahuan Ibu Hamil Tentang Bayi Berat Lahir Rendah (BBLR)}

Pengetahuan merupakan faktor yang penting untuk terbentuknya perilaku seseorang, karena dari pengalaman dan penelitian terbukti bahwa perilaku yang didasari pengetahuan akan lebih langgeng dari perilaku yang tidak didasari oleh pengetahuan (Notoatmodjo, 2010).

Faktor-faktor yang bisa mempengaruhi pengetahuan ibu hamil tentang bayi berat lahir rendah (BBLR) adalah pengalaman, keyakinan, fasilitas, dan sosial budaya yang tidak mendukung. Pengetahuan dapat dipengaruhi oleh pendidikan, ekonomi, sosial budaya, dan politik. Faktor-faktor yang dapat mempengaruhi kurangnya pengetahuan ibu hamil tentang bayi berat lahir rendah antara lain ibu hamil yang kurang kesadaran tentang pentingnya menjaga kesehatan khususnya yang berkaitan dengan kesehatan selama kehamilan agar bayi lahir dengan sehat dan tidak terjadi masalah yang berhubungan dengan bayi berat lahir rendah (BBLR), kurangnya informasi dari tenaga kesehatan tentang bahaya bayi berat lahir rendah (BBLR), 
kurangnya sosialisasi berkaitan dengan bayi berat lahir rendah, kurangnya kemampuan dari ibu hamil untuk memahami informasi yang diberikan oleh petugas kesehatan (Notoatmodjo, 2003).

Hasil penelitian tingkat pengetahuan ibu hamil tentang bayi berat lahir rendah (BBLR) berdasarkan tabel 4.7 menunjukkan bahwa dari 85 responden yang memperoleh kriteria baik sebanyak 22 responden atau $(25,88 \%)$, yang memperoleh kriteria cukup sebanyak 47 responden atau $(55,30 \%)$, dan yang mempunyai kriteria kurang sebanyak 16 responden atau $(18,82 \%)$.

Berdasarkan penelitian yang telah dilakukan dapat ditarik kesimpulan bahwa pengetahuan ibu hamil tentang bayi berat lahir rendah di Puskemas Massenga Kecamatan Polewali Kabupaten Polewali Mandar tahun 2015 berada pada kategori pengetahuan cukup. Hal ini sesuai dengan sub variabel yang telah diuraikan sebelumnya. Jadi jelaslah bahwa pengetahuan responden sangat dipengaruhi oleh tingkat pendidikan baik formal maupun informal, informasi dan pengalaman.

Dibawah ini akan dijelaskan tentang analisa antara pengetahuan responden tentang anemia berat dengan karakteristik dari segi umur, pendidikan maupun pekerjaan responden.

Pengetahuan ibu hamil tentang bayi berat lahir rendah (BBLR) jika dikaitkan dengan karakteristik umur responden dalam hal ini menunjukkan bahwa pada kelompok umur tersebut responden terbanyak berada pada usia subur yaitu sebanyak 68 responden atau (80\%). Kebanyakan ibu hamil yang belum mengetahui yang dimaksud dengan pengertian, tanda-tanda, dan penyebab bayi berat lahir rendah (BBLR) sehingga hal ini mempengaruhi tingkat pengetahuan ibu hamil tentang bayi berat lahir rendah (BBLR) berada pada kategori cukup.

Berdasarkan analisa peneliti menunjukkan bahwa pengetahuan ibu hamil dipengaruhi oleh usia dimana usia ini berada pada usia subur yang dari segi pengetahuan cukup baik, karena sudah cukup mempunyai pengalaman tentang kesehatan dan kemampuan untuk memahami informasi yang diperoleh, pengetahuan seseorang juga dipengaruhi oleh tingkat pengalaman ibu hamil serta kesadaran dan motivasi ibu hamil untuk memperoleh pengetahuan tentang bayi berat lahir rendah (BBLR).

Sedangkan pengetahuan responden tentang bayi berat lahir rendah (BBLR) berdasarkan karakteristik berdasarkan tingkat pendidikan ibu hamil yang mayoritas berpendidikan SMA yaitu sebanyak 61 responden atau $(71,76 \%)$, namun pengetahuan ibu hamil tentang bayi berat lahir rendah (BBLR) masuk dalam kategori cukup, hal ini bertolak belakang dengan pendidikan responden, sehingga dapat peneliti menyimpulkan pendidikan yang tinggi tidak dapat menjadi patokan responden tersebut mempunyai pengetahuan yang cukup tentang bayi berat lahir rendah.

Pengetahuan cukup dapat dipengaruhi oleh pengalaman dan kamauan responden untuk mencari informasi tentang bayi berat lahir rendah, dimana responden masih membutuhkan pengetahuan tentang penyebab dan tanda-tanda dari bayi berat lahir rendah (BBLR) sehingga masih sangat diperlukan pengetahuan responden sejak masa kehamilan sehingga resiko bayi berat lahir rendah (BBLR) dapat dicegah.

Pendidikan adalah proses perubahan sikap dan perilaku seseorang atau kelompok orang dalam mendewasakan manusia melalui upaya pengajaran dan pelatihan (Jannah marmy, 2007).

Pengetahuan responden tentang bayi berat lahir rendah (BBLR) juga dipengaruhi oleh karakteristik dari segi pekerjaan ibu hamil yang dimana tertinggi yaitu sebagai IRT sebanyak 58 respoden atau $(68,23 \%)$ dimana pekerjaan diperkirakan dapat mempengaruhi pengetahuannya tentang bayi berat lahir rendah (BBLR). 
Menurut analisa peneliti pekerjaan tertinggi responden adalah IRT yang dimana meskipun responden hanya sebagai ibu rumah tangga yang sibuk dengan mengurusi pekerjaan rumah tangga tetapi ibu hamil masih mempunyai kemauan untuk mencari informasi khususnya yang berkaitan dengan kesehatannya selama kehamilan karena ibu hamil menganggap informasi tentang kesehatan itu sangat penting selain untuk menjaga kesehatan ibu dan bayi juga sebagai deteksi dini agar kejadian bayi berat lahir rendah (BBLR) dapat dicegah sejak masa kehamilan.

\section{KESIMPULAN DAN SARAN Kesimpulan}

Dari penelitian yang telah dilakukan terhadap 85 responden dengan tingkat pengetahuan ibu hamil tentang bayi berat lahir rendah (BBLR) dapat diperoleh kesimpulan.

1. Tingkat pengetahuan ibu hamil tentang pengertian bayi berat lahir rendah (BBLR) tertinggi diperoleh pada kategori cukup yaitu 43 (50,59\%) responden.

2. Tingkat pengetahuan ibu hamil tentang tanda-tanda bayi berat lahir rendah (BBLR) tertinggi diperoleh pada kategori kurang yaitu $35(41,18 \%)$ responden.

3. Tingkat pengetahuan ibu hamil tentang penyebab bayi berat lahir rendah (BBLR) tertinggi diperoleh pada kategori cukup yaitu $49(57,65 \%)$ responden.

4. Secara keseluruhan tingkat pengetahuan ibu hamil tentang bayi berat lahir rendah (BBLR) di Puskesmas Massenga Kecamatan Polewali Kabupaten Polewali Mandar tahun 2015 dari 85 responden berada pada tingkat pengetahuan yang cukup 47 $(55,30 \%)$, persentase diatas jika dimasukkan dalam kriteria standar objektif Arikunto, tingkat pengetahuan responden tersebut berada pada kategori cukup.

\section{DAFTAR PUSTAKA}

Aziz Alimul Hidayat. 2008. Asuhan Neonatus Bayi dan Balita .Jakarta :kedokteran EGC

Nadjibah Y. 2011. Problematikan Selama Kehamilan. Jakarta : PT Tiga Serangkai Pustaka Mandiri

Notoatmodjo S. 2007. MetodologiPenelitianKesehatan. Jakarta : PT RinekaCipta

NotoatmodjoS. 2010 MetodologiPenelitianKesehatan. Jakarta :PTRinekaCipta.

\author{
Prawirohardjo, \\ S., \\ 2009.Bukupanduanpraktispelaya \\ nankesehatan maternal dan \\ neonatal.Jakarta: \\ YayasanBinaPustakaSarwonoPra \\ wirohardjo.
}
Rukiyah Ai Yeyeh,dkk. 2009. AsuhanKebidanan 1 (Kehamilan).Jakarta : Trans Info Media
Rukiyah Ai $\quad 2009$. AsuhanNeonatusBayidanAnakBal itaEdisiRevisi.Jakarta : Trans Info Media

Proverawati, Atikah, dkk. (2009) Buku Ajar GiziUntukKebidanan. Yogyakarta: NuhaMedika 
Sulistyawati

A,2009.

AsuhanKebidananPadaMasaKeh amilan. Jakarta: salembaMedika

Taqwim Ali, IMS. NurahManoe. 2006. Hubunganantaraberatbadanlahir dengan status giziibuberdasarkanukuranlingkar lenganatas.http://med.unhas.ac.i $d$, diaksestanggal 17-02-2015.

Vivian Nanny L,dkk. 2011. AsuhanKehamilanUntukKebidan an. Jakarta:SalembaMedika

ZaenabHerawati, Tim peneliti. 2006. Beratbadanlahirrendah (BBLR), archive.html.

http://blogjoeharno.blogspot.com,di aksestanggal17-02-2015. 